\title{
Design of Global Positioning System Based on Single Chip Microcontroller
}

\author{
Yong $\mathrm{He}^{1, \mathrm{a}}$, Yanan Chen ${ }^{2, \mathrm{~b}}$
}

1School of Information Engineering, Beijing Institute of Fashion Technology, Beijing, 100029, China 2School of Information Engineering, Beijing Institute of Fashion Technology, Beijing, 100029, China

aemail: 316055535@qq.com, bemail: gxycyn@bift.edu.cn

Keywords: STC89C52 Single Chip Microcontroller; GPS Positioning; LCD1602

\begin{abstract}
This paper introduces a kind of GPS positioning terminal device with the STC89C52 microcontroller as its control core in detail. This device consists of 52 single chip microcontroller and some peripheral circuit, GPS modules, liquid crystal display module and serial communication interface, and can show simple latitude and longitude information to realize location tracking in the outdoor. At the same time, it can display the location of the specific information clearly in the BaiDu map through USB interface. It can be applied to vehicle positioning, smart clothing and the tracking and protection of wildlife and so forth.
\end{abstract}

\section{Introduction}

GPS positioning technology is in using of GPS satellite, the user receiver on the ground in real time to launch L-band carrier frequency ranging signal, the user receiver for continuous reception, and calculate the location of the receiver antenna to complete the navigation, timing and other related functions. In the field of geodesy, vehicle navigation, smart clothing and timing calibration, GPS positioning system can display the corresponding real-time position and speed and other parameters.

\section{System overall design}

The system is a portable device with small size and easy operation. The system firstly receives the satellite data from the GPS module. The module transmits the data information to the MCU through the serial communication interface. The single chip processor STC89C52 is used as the core processor to separate the NMEA0183 standard statement sent by the GPS module and extract the key positioning information. The LCD 1602 displays the positioning information. At the same time, the device can also be connected to the PC through the USB interface, and in the form of Baidu Map displayed the specific location information clearly. The overall structure of the system block diagram shown in Diagram 1:

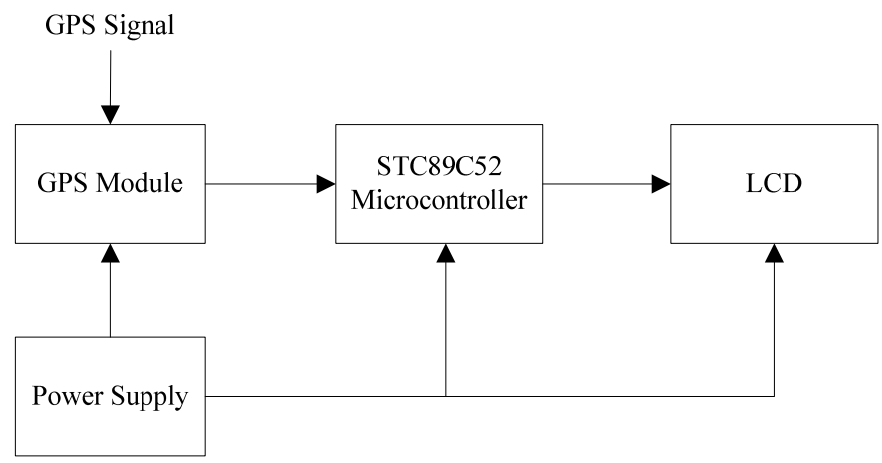

Diagram 1 System overall structure 


\section{Hardware design of the system}

\subsection{Control part}

This design control part is composed of STC89C52 microcontroller chips and basic circuit element of clocking circuit and reset circuit, etc. We have adopted the minimum system board (see Figure 1), which not only has a microcontroller chip (replaceable), but also a basic peripheral circuit, including the clock circuit and reset circuit, as well as the necessary pull-up resistor P0 port.

At first, the minimum system board with a pin header way export the 40 pin of 52 microcontrollers, with the common DuPont line can be a simple electrical connection. then, with 5, $+5 \mathrm{~V}$ and GND external expansion pin, more convenient to use other expansion equipment. At last the serial port separates lead to facilitate the download, Users can simply use TTL to USB bridge programming to 52 microcontrollers.

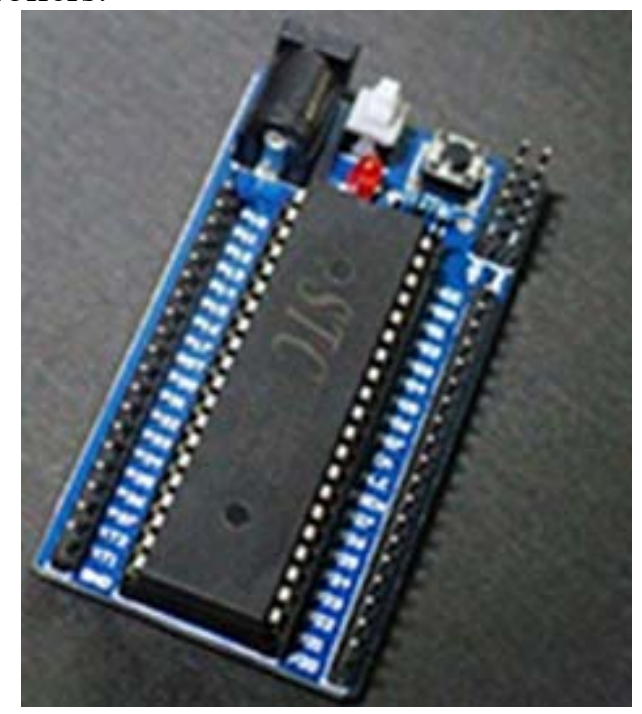

Fig. 1 The minimum system board physical figure

3.2 Receiving part--GPS receiving module

This design adopts Ublox company NEO-6M GPS module, The product comes with EEPROM, can save configuration information, with IPX antenna interface can be connected to the active antenna, with USB Micro interface, can use PC software, self-serial function, and Compatible with all types of microcontrollers.

3.2.1 Connecting the GPS module and single-chip microcontroller

As is showed in the Figure 3, the circled part 1 is the serial communication port of the GPS module. And it can connected with microcontroller practically as we can see in the Digram 2:

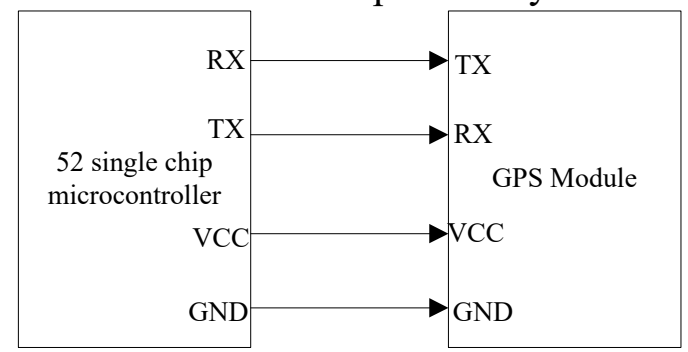

Diagram 2 The connection between GPS module and $52 \mathrm{MCU}$

\subsubsection{Selecting the antenna of GPS module}

There is a passive ceramic antenna inside the GPS receiver, however, the effect of searching satellites is not good enough. We add an active antenna powered by $3 \mathrm{~V}$ source in the interface, such as figure 2: 


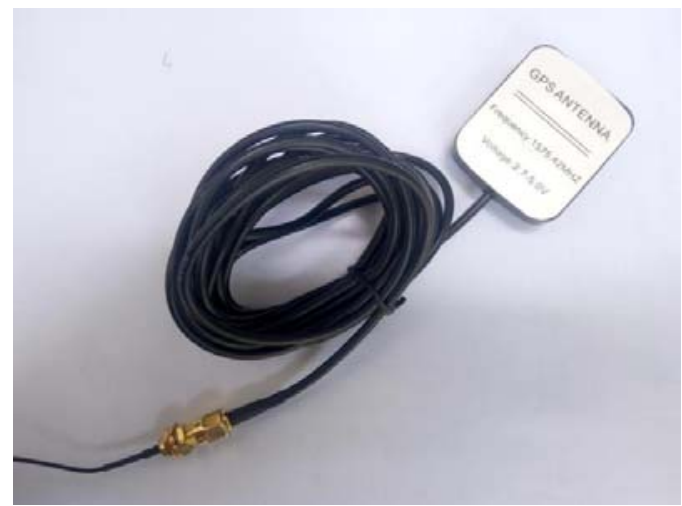

Fig. 2 Active antenna

3.3 Supplying power for the whole system

This system is powered by USB device. The 52 minimum system lead out its 40 pins while the GPS module have $+5 \mathrm{~V}$ pin and Micro USB interface, making it possible to supply power for the whole system by devices with USB interface, such as Mobile Power, PC and so on. The method of supplying power for the overall system as Diagram 3:

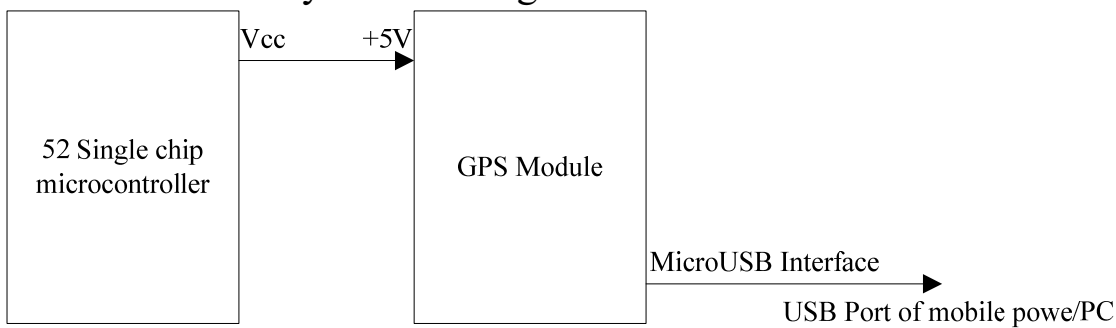

Diagram 3 Supplying power for the overall system

3.4 The hardware connection of the whole system

Check List: 52 minimum system, Breadboard, special connection wire for breadboard, DuPont Line, NEO-6M GPS module, GPS active antenna, LCD1602 display screen, 10K potentiometer. The hardware connection of the whole system as Diagram 4: 


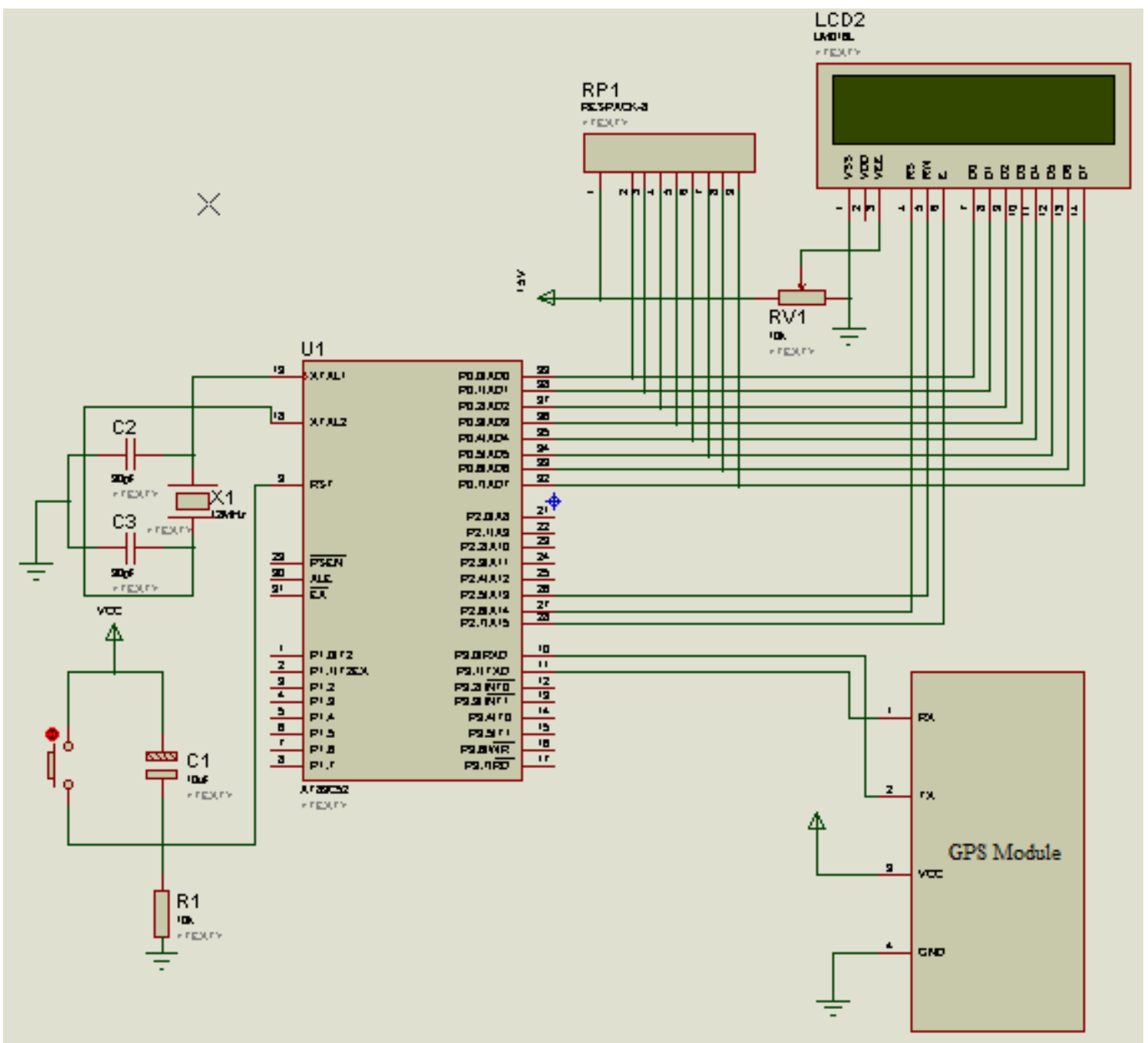

Diagram 4 The hardware connection of the overall system

\section{The software part design of the system}

4.1 The overall software part design

The overall flow chart of the software part as showed in Diagram 5: 


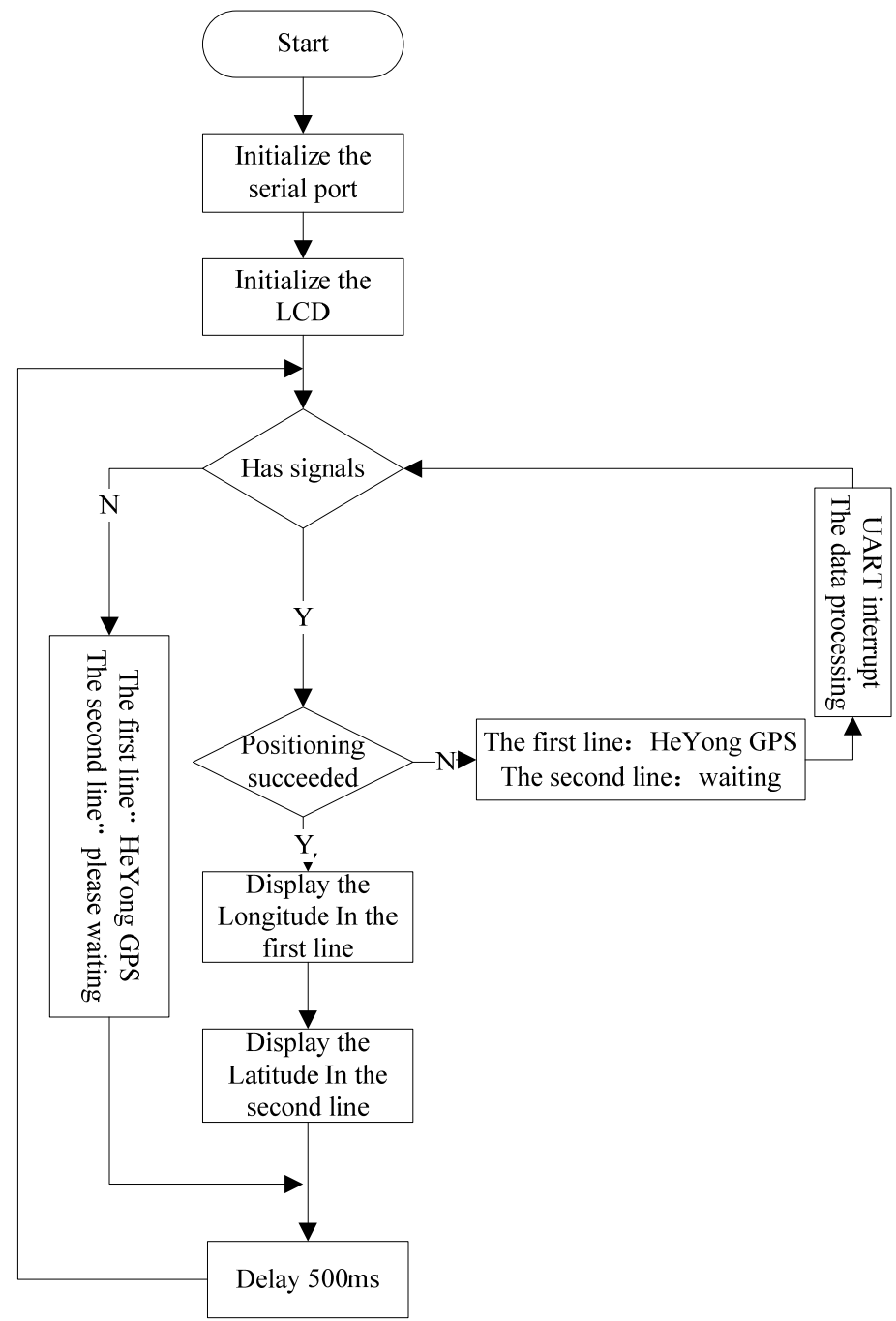

Diagram5 The overall flow chart of the software part

4.2 Setting the initialization of the timer

Four kinds of serial port works corresponding to three kinds of Baud Rate, their computation formula is different:

The Baud Rate of way $0=$ fosc $/ 12$

The Baud Rate of way $2=(2 \mathrm{SMOD} / 64) \times$ fosc

The Baud Rate of way $1=(2 \mathrm{SMOD} / 32) \times\left(\mathrm{T} 1_{\text {the overflow ratio }}\right)$

The Baud Rate of way $3=(2 \mathrm{SMOD} / 32) \times\left(\mathrm{T} 1_{\text {the overflow ratio }}\right)$

The overflow ratio of Timer $1=\frac{f_{\text {osc }}}{12}\left(\frac{1}{2^{k}-\text { initial value }}\right)$

K--the digit of Timer1, it is related to the setting method of Timer1. If Timer1 works under way 0 , then $\mathrm{K}=13$; else if, Timerl works under wayl, then $\mathrm{K}=16$; else, then $\mathrm{K}=8$.

$$
\therefore \mathrm{T} 1_{\text {initial value }}=2^{\mathrm{K}}-\frac{2^{\mathrm{SMOD}}}{32} \times \frac{\mathrm{f}_{\text {osc }}}{12 \times \text { BaudRate }}
$$

With Timer1 as the Baud generator (way 2) in the system, we use Timer 0 combining a variable for timing $500 \mathrm{~ms}$ as the output cycle of LCD1602 to initialize it. Baud Rate is $9600 \mathrm{~b} / \mathrm{s}$, lock frequency is $11.0592 \mathrm{MHZ}$, then we can calculate:

$$
\mathrm{TH} 1=\mathrm{TH} 0=2^{8}-\frac{2^{0}}{32} \times \frac{11.0592 \times 10^{6}}{12 \times 9600}=253(F D)
$$

4.3 The part of GPS decoding display

What the GPS module putout is data stream in the standard of NMEA--0183. The data stream 
contains a number of different statements, which contain different information and in different format. Generally, it is by serial port interrupt that we receive the information from the GPS module, and extract some useful information. At first, we need to identify the different statement. Then using corresponding algorithm to extract the information it contains.

After processing, the information can display on the LCD1602 optionally. In our system, the latitude is displayed on the first line, while the longitude on the second line. The Diagram 6 is how to process the positioning data.

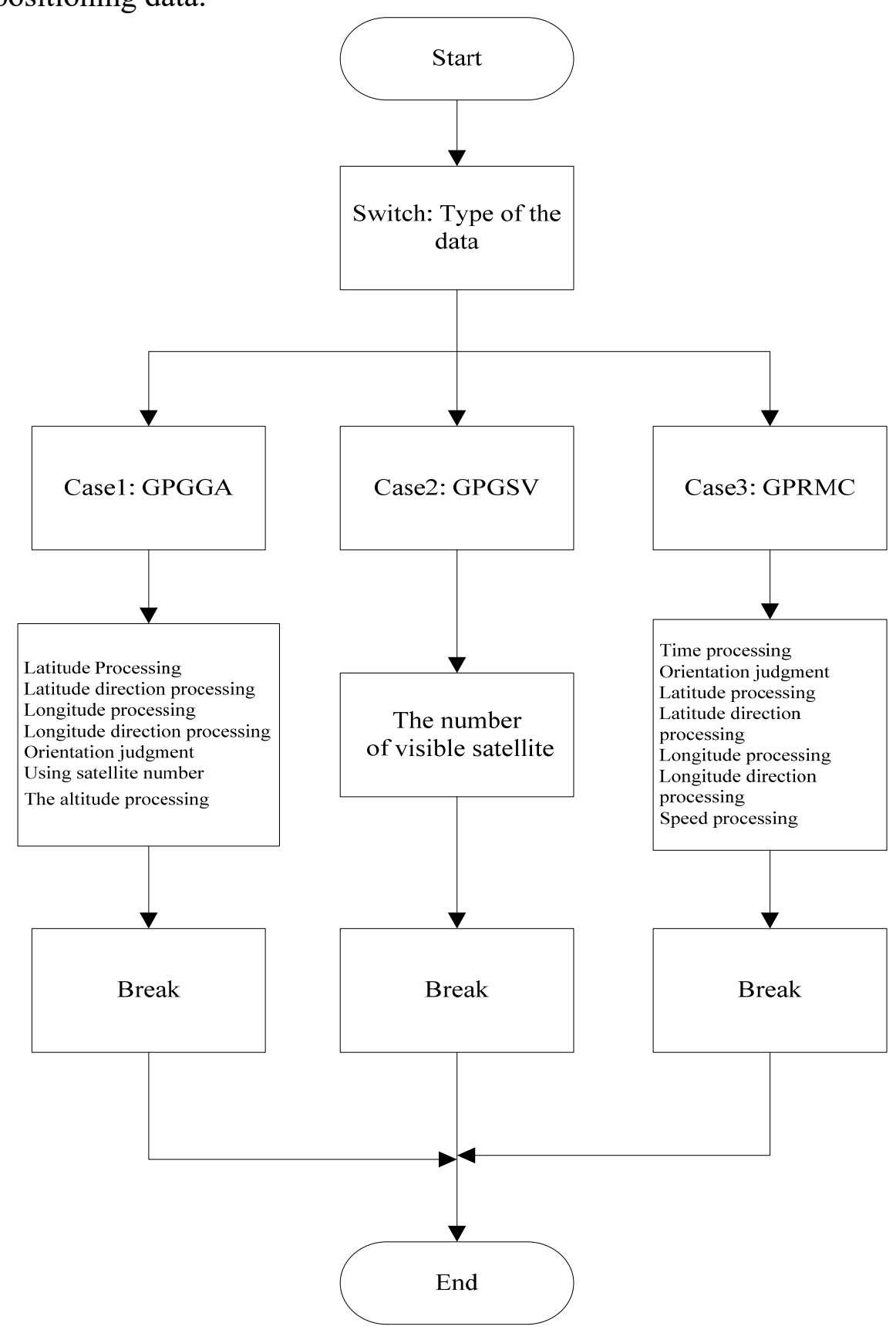

Diagram 6 Processing the positioning data

\section{System debugging}

Because the result of searching satellite is better when placing the GPS module in open place, we select three site to debug the system: in the fourth student dormitory building of BIFT, in front of The third classroom building, and the playground. It is necessary to put the active antenna out the window and its black side down, for the indoor closed condition. Following just select the playground to show our test result as Figure 3 and Figure 4. 


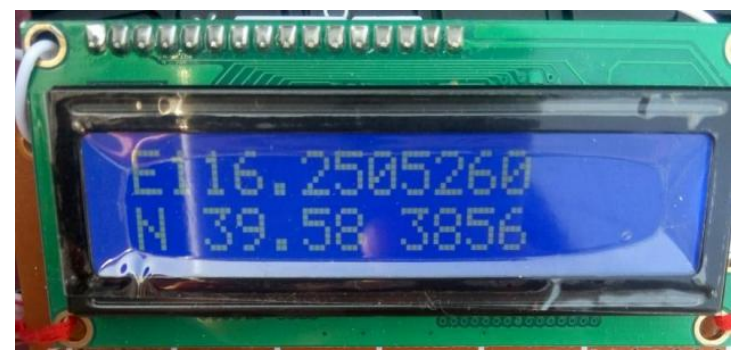

Fig.3 The result of LCD1602 in playground

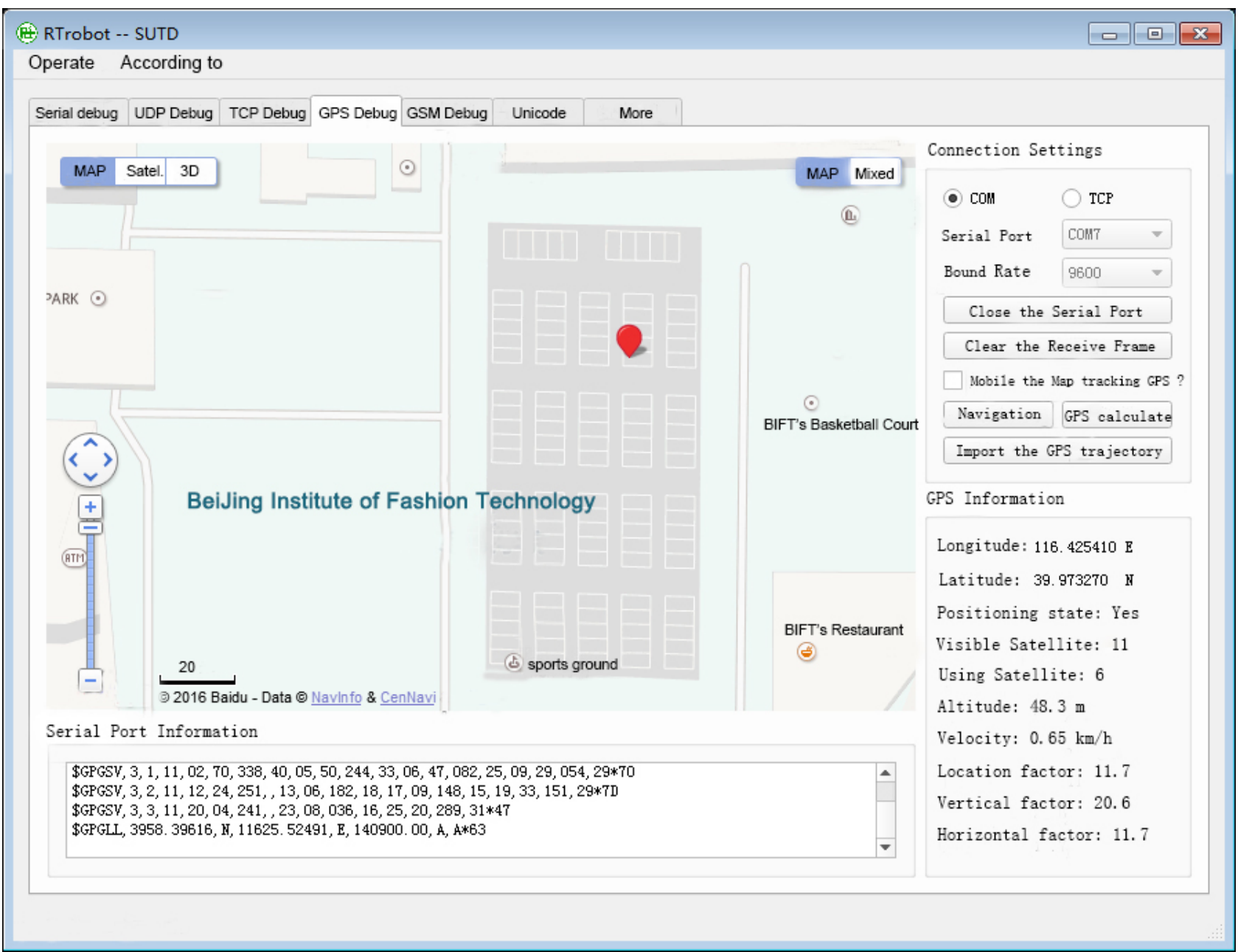

Fig. 4 The result of BaiDu Map in playground

Analysis of result tested in different place by different platform, including LCD1602, u-center, and BaiDu Map.

Table 1 The comprehensive analysis of testing result

\begin{tabular}{|c|r|r|r|r|r|r|}
\hline Site & \multicolumn{2}{|c|}{ LCD1602 } & \multicolumn{2}{c|}{ u-center test software } & \multicolumn{2}{c|}{ BaiDu Map } \\
\hline $\begin{array}{c}\text { In the fourth } \\
\text { student } \\
\text { dormitory }\end{array}$ & longitude & E116.2506476 & longitude & E116.2564514 & longitude & E116.2566314 \\
\cline { 2 - 7 } & latitude & $\mathrm{N} 39.5841240$ & latitude & $\mathrm{N} 39.5841078$ & latitude & $\mathrm{N} 39.5841780$ \\
\hline $\begin{array}{c}\text { In front of the } \\
\text { 3th classroom }\end{array}$ & longitude & E116.2505214 & longitude & E116.256131 & longitude & E116.255186 \\
\cline { 2 - 7 } & latitude & $\mathrm{N} 39.5831180$ & latitude & $\mathrm{N} 39.5838648$ & latitude & N39.5830560 \\
\hline $\begin{array}{c}\text { In the } \\
\text { playground }\end{array}$ & longitude & E116.2505217 & longitude & E116.2552538 & longitude & E116.255246 \\
\cline { 2 - 7 } & latitude & $\mathrm{N} 39.5839190$ & latitude & latitude & latitude & N39.5839620 \\
\hline
\end{tabular}

From above the table, it can be ascertained that the design realized the accuracy up to two digital 
after degree.

\section{Conclusion}

We design the interface circuit of the module and the single chip microcontroller based on the existed GPS module. In addition, this paper provides the principle of separating and extracting useful information from the date stream outputted by the GPS module. Above the mentioned hardware interface circuit and program designed thought has been applied successfully into the outdoor experiments, and displayed the results correctly. The equipment is easy to operate and has a wide range of application prospect.

\section{References}

[1] Fuzhao Zhong. 8051 single chip microcontroller principle and its hardware and software design[M]. Beijing: Beijing university of aeronautics and astronautics press, 2014: 168-199.

[2]Bo Liu. 51 single chip microcomputer application development example: Based on the Proteus simulation[M]. Beijing: Electronic industry press, 2014: 122-133.

[3] Mingjing Deng. The principle and application of global positioning system (GPS) measurement[M]. Chendou: Southwest jiaotong university press, 2014.

[4] Li qiang et al. Theory of GPS, is big and application [M]. Tsinghua university press, 2011.

[5] u-center GNSS evaluation software for Windows User Guide[EB/OL]. U-blox LTD., 2015. 